\title{
Jacques Ellul, Théologie et Technique. Pour une éthique de la non-puissance
}

Textes établis par Sivor, Danielle et Yves Ellul

Introduction de Frédéric Rognon.

Genève, Labor et Fides, coll. « Philosophie », 2014, 376 p.

Daniel Vidal

\section{(2) OpenEdition}

Journals

Édition électronique

URL : http://journals.openedition.org/assr/26396

DOI : $10.4000 /$ assr.26396

ISSN : $1777-5825$

Éditeur

Éditions de l'EHESS

\section{Édition imprimée}

Date de publication : 31 décembre 2014

Pagination : 179

ISBN : 978-2-7132-2467-6

ISSN : 0335-5985

Référence électronique

Daniel Vidal, « Jacques Ellul, Théologie et Technique. Pour une éthique de la non-puissance », Archives de sciences sociales des religions [En ligne], 168 | 2014, mis en ligne le 15 avril 2015, consulté le 10 décembre 2020. URL : http://journals.openedition.org/assr/26396 ; DOI : https://doi.org/10.4000/assr. 26396

Ce document a été généré automatiquement le 10 décembre 2020.

(c) Archives de sciences sociales des religions 


\section{Jacques Ellul, Théologie et Technique. Pour une éthique de la non-puissance}

Textes établis par Sivor, Danielle et Yves Ellul Introduction de Frédéric Rognon.

Genève, Labor et Fides, coll. «Philosophie », 2014, 376 p.

Daniel Vidal

\section{RÉFÉRENCE}

Jacques Ellul, Théologie et Technique. Pour une éthique de la non-puissance

Textes établis par Sivor, Danielle et Yves Ellul

Introduction de Frédéric Rognon.

Genève, Labor et Fides, coll. « Philosophie », 2014, 376 p. 
1 «Le critère de ma pensée est la révélation biblique; le contenu de ma pensée est la révélation biblique; le point de départ m'est fourni par la révélation biblique; la méthode est la dialectique selon laquelle nous est faite la révélation biblique. » Par cette confession d'une foi essentielle et sans nuage aucun - énoncée dans son ouvrage Le vouloir et le Faire (voir note critique dans ce même numéro), et promue, selon les termes de Frédéric Rognon en sa préface, «au rang d'hypostase » - Jacques Ellul pose l'impératif absolu et fondateur d'une théologie radicalement objectée à la Technique, ce Léviathan moderne dont il n'a cessé de dénoncer la toute-puissance et le risque mortel qu'elle fait peser sur la part humaine de l'homme. Ce texte, daté des années 1975 et jusqu'alors inédit, vaut

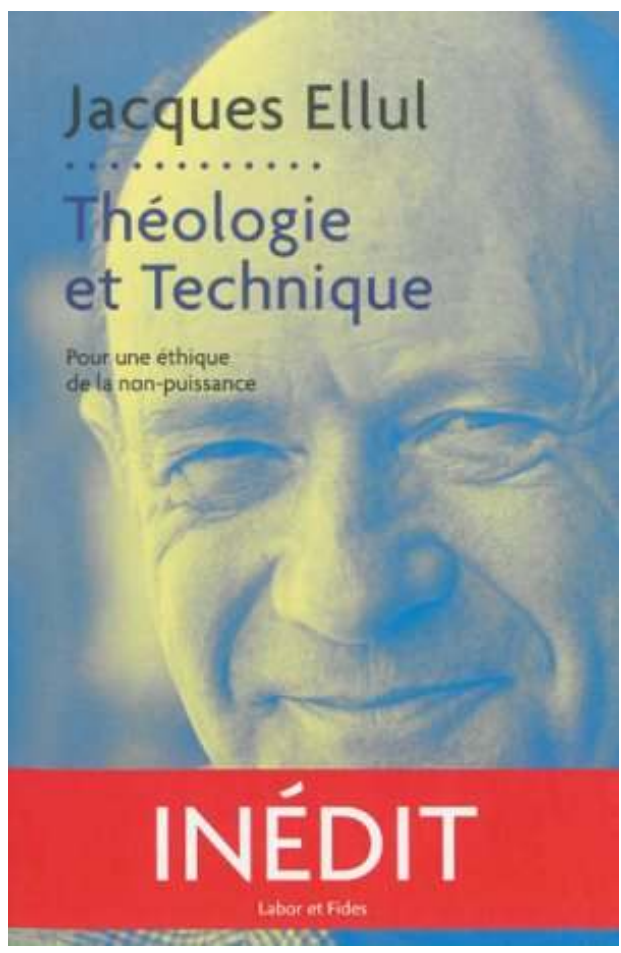
pour sa radicalité, sa «brutalité

d'ébauche ", son caractère ingénument provocateur - et c'est déjà beaucoup. De La Technique ou l'enjeu du siècle (1954), au Système technicien (1977) et au Bluff technologique (1988), la critique de ce monde totalitaire de la nécessité constitue le fil rouge d'une pensée attentive à ce qui risque de précipiter l'homme vers un « suicide collectif », nul espace de liberté ne s'offrant à lui dans la logique purement productiviste de la Technique triomphante. La Technique est ce monstre froid que l'homme érige en sacré, à quoi il faut opposer une "vigoureuse profanation ». Cette "profanation " sera le rappel d'une foi en une Transcendance, Parole et Présence de l'Évangile. Revenir à la source du christianisme pour se libérer de l'implacable logique technicienne. Car la Technique est cette exaltation de la praxis qui recouvre la totalité de la vie des hommes, assujettis aux exigences d'une croissance technique exponentielle, incontrôlable, aveugle et dévastatrice. Monstre froid? Oui, car sans historicité, en dehors de toute critique, de toute dialectique, de toute "existence organique", principe et pratique dénués de toute morale et de toute éthique. La technique, ou l'univers de la Chose. "Chose indifférente au point de vue théologique ", écrit Ellul, ne relevant d'aucun jugement, ou, plus exactement, se déployant sous condition d'ignorance de toute valeur. Monde de la Chose et monde des Moyens obéissant à leur propre loi, "univers des doubles et des duplicata ", qui composent un Système réglé par les principes d'unicité et d'universalité.

2 La Technique, selon Ellul, "enferme l'homme dans sa finitude ", soumise aux seuls impératifs de normalité, efficacité, réussite, travail. Sans repères, sans limites. Le temps n'y est qu'un présent sans cesse reconduit. La société technicienne ne génère " aucun rapport d'altérité », mais "une systématisation qui enferme l'homme dans un Même perpétuel. » Système « englobant, total, inévitable, inattaquable » Où tout, en effet, se transforme en chose. Monde réifié, univers de l'homme devenu Nature, et destin. Fatalité, écrit l'auteur, sans référence extérieure, sans ouverture. Monde « sans issue ». 
Dans cette sacralisation de la Technique, où la seule incarnation demeure l'esprit de puissance - Ellul ne pense jamais ce monde en termes de jouissance, qui supposerait une théorie du désir, absente, forcément absente, de la « raison » technicienne - une théologie est-elle possible? Sans doute, mais le philosophe nous précise que «tout ce qui est réduit à ne plus être qu'opération technique cesse de concerner le christianisme ". À cette réserve près, mais combien essentielle pour l'auteur, on s'en doute, la théologie propre au « royaume » de la Technique répond à ses réquisits. Elle sera " agnostique " (« on ne sait rien de Dieu ni d'une hypothétique révélation»); elle sera « concrète » (« tournée vers le seul réel constatable [...] évacué tout le domaine du spirituel»); elle sera "horizontale " ("à hauteur d'homme: il n'y a rien d'autre ni nulle part»). Théologie pour temps de désenchantement. La foi est vécue comme affaire purement intime et personnelle. Triomphe de la subjectivité, qui signe en même temps l'enfermement de la personne en elle-même, et du sujet en sa propre économie.

Il faut donc renverser les tables de cette Loi. Sortir de la nécessité de la puissance, de l'impératif d'efficacité, de cet univers mortifère des Choses, et proposer une alternative globale au désespoir du monde, qui sera alternative au monde lui-même. Et qui serait peut-être une proposition mystique pour notre temps? « Là où la vie de l'homme est en jeu, la Révélation est en jeu ». Contre la Technique, donc, la Révélation. Christique, à coup sûr, mais à condition de savoir (mais d'où, ce « savoir »?) que « Jésus-Christ n'est rien sans un Transcendant qu'il est venu révéler, qui est l'Être absolu, tout entier présent et devenu [en Jésus-Christ seul] immanent». Si la Technique est bien ce système clos sur lui-même, indifférent et indifférencié, négateur de toute altérité, on conçoit que seul «le Transcendant pur, parce que extérieur et strictement inassimilable » est capable de fournir un " point de référence » et d'altérité ouvrant le monde humain à son horizon de liberté. À la reproduction infinie du " même ", à quoi la Technique assujettit l'homme, la Révélation libère la possibilité «de dire oui ou non », instaure le conflit, la transgression, crée des tensions et des crises. La Révélation, cet autre nom de la "Création", qui en finit avec la "nature», ce destin dans la « chose » écrit. Coup de force? Non; coup de grâce. Seule la quête d'une signification « externe » peut, selon la formule de Ellul, « dé-signifier la Technique ». La Révélation est, pour le philosophe, cette "marque spécifique de l'homme" libéré du temps "chronologique et artificiel» capable alors de décider d'un avenir - d'une advenue. Penser le temps comme relation entre le novum et l'escaton, entre cette "nouveauté que l'homme peut faire apparaître », et qui ne dérive ni de la Nature ni de l'Histoire, concepts inhérents à la Technique, et cette " fin », cet " ultime sans cesse présent dans le cours de la vie et vécu dans la foi ». C'est en cette tension permanente entre naissance à soi-même et accomplissement en soi du «Transcendant» que l'homme rencontre sa condition proprement humaine.

4 La Révélation est la reconnaissance d'un "Transcendant qui agit et qui est en luimême »- extérieur absolu, et par là interdisant au monde " de se clore dans un système total ». Par cette extériorité " une ouverture est toujours possible ». L'auteur nomme "l'ultime», l'eschatologique, cette «anticipation du retour du Christ ici et maintenant ", qui " pénètre le temps, l'écartèle » et conjoint l'homme non pas à son dieu, mais à «son point d'attente». À son Altérité. Sans que cet homme à ce dieu se confonde, pas plus, écrit-il, que ne se conjoignent « le ciel et la terre ». Dieu est « absolu sans aucun compromis». La Révélation est l'assentiment à cette effraction, cette irruption, et à cet «inattendu chaque fois provoquant un nouveau». Il faut cette rupture pour mettre fin au règne de la Technique, et, auraient pu dire les surréalistes, 
que vienne "l'homme total dans un monde libéré». Total ne signifie pas illimité. L'auteur écrit qu' "être homme, c'est être contre nature ", proposition élémentaire sans doute, mais qui invite à penser tel homme comme requérant seuils et limites, quand la nature, précisément, ne relève «d'aucune régulation globale». L'illimité « est la négation de l'humain et de la culture ». Et l'objet même du sacré est la limite. Le temple, cet espace maîtrisé, interdit, réservé, etc. C'est à ce prix que le désordre est viable, et que des «maîtres" peuvent le prendre en charge. Contre la toute-puissance illimitée de la Technique, contre l'efficacité érigée en valeur suprême, Ellul prône une éthique de la non-puissance, cette limite objectée à l'univers des choses et leur comptabilité. Et, contre le temps de la Technique, chronologique, mesuré et productif, temps de la "malédiction », de la «chute » - un temps ouvert à son incertitude, peutêtre sa jouissance, temps à tout le moins désengagé de tout travail, de toute finalité, temps "pour rien", sabbat. Comme au septième jour. Rébellion d'une pensée protestante contre un esprit de Réforme, et une éthique que Weber mit au net. Au nom d'une foi libérée de tout soupçon. 